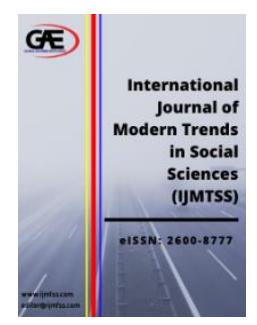

\author{
INTERNATIONAL JOURNAL OF \\ MODERN TRENDS IN \\ SOCIAL SCIENCES \\ (IJMTSS) \\ www.ijmtss.com
}

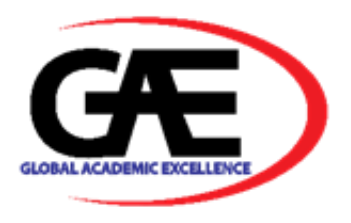

\title{
RELATIONSHIP BETWEEN NEGATIVE CAREER THOUGHTS AND SELF-EFFICACY WITH CAREER DECISION-MAKING DIFFICULTIES AMONG FIRST YEAR UNDERGRADUATE STUDENTS OF UPM
}

\author{
Nur Azreen Md Sanusi ${ }^{1}$, Zanariah Ismail ${ }^{2 *}$ \\ 1 Department of Human Development and Family Studies, Faculty of Human Ecology, Universiti Putra \\ Malaysia \\ Email: 187950@student.upm.edu.my \\ 2 Department of Human Development and Family Studies, Faculty of Human Ecology, Universiti Putra \\ Malaysia \\ Email: zanariah_i@upm.edu.my \\ Corresponding Author
}

\section{Article Info: \\ Article history: \\ Received date: 13.07.2020 \\ Revised date: 10.09 .2020 \\ Accepted date: 10.12 .2020 \\ Published date: 15.12 .2020 \\ To cite this document:}

Sanusi, N. A. M., \& Ismail, Z. (2020). Relationship Between Negative Career Thoughts and Self-Efficacy With Career Decision-Making Difficulties among First Year Undergraduate Students of UPM. International Journal of Modern Trends in Social Sciences, 3 (14), 162172.

DOI: $10.35631 /$ IJMTSS.3140013

\begin{abstract}
:
The purpose of this study is to determine the relationship between negative career thoughts and self-efficacy with career decision-making difficulties among first-year undergraduate students of UPM. The sample for this study consisted of 368 first-year undergraduate students of UPM and participants were recruited using stratified random sampling. A self-administered questionnaire was used to collect information. Career Thoughts Inventory was utilized in this study to measure negative career thoughts. General Self-efficacy Scale was utilized to measure self-efficacy. Other than that, the Career Decision-Making Difficulties Questionnaire was utilized to measure career decision-making difficulties. The results revealed that most of the respondents had a high level of self-efficacy $(62.2 \%)$. Pearson correlation analysis demonstrated that there was a positive significant relationship between negative career thoughts (decision-making confusion) and career decision-making difficulties (lack of information; $\mathrm{r}=0.595, \mathrm{p}<0.01$ and inconsistent information; $\mathrm{r}=$ $0.579, \mathrm{p}<0.01)$. Besides, there was also a significant positive relationship between negative career thoughts (commitment anxiety) and career decision-making difficulties (lack of information; $r=0.588$, $p<0.01$ and inconsistent information; $r=0.572, p<0.01)$. In addition, there was a significant negative relationship between self-efficacy and career decision-making difficulties (lack of information; $r=-0.388, p$ $<0.01$, inconsistent information; $\mathrm{r}=-0.298, \mathrm{p}<0.01)$. Therefore, the
\end{abstract}



efficacy are important to understand the patterns of difficulties in career decision-making among first-year undergraduate students of UPM. Furthermore, further research could be expanded in different academic institutions in another region with a bigger sample to promote a better generalization of findings and yield more reliable data

Keywords:

Negative Career Thoughts, Self-Efficacy, Career Decision-Making Difficulties, First Year Undergraduate Students

\section{Introduction}

Tertiary education acts as one of the significant roles in career development and becomes an important pathway for career success. Nowadays, the real-life situation reveals that the number of university graduates is increasing year by year and facing tough competition in the job market (Moaz Nair, 2018). There are more than 200,000 students graduate from tertiary education every year and 1 out of 5 graduates were unemployed which mainly contributed by the Degree holders that make up a total of $35 \%$ of graduate unemployment (Leo, 2018). In general, university students are making headlines and topics of conversation particularly in graduate unemployment issues because the university can no longer secure jobs for the students in these past few years. This phenomenon will bring limitations to their future career planning and make them even harder to engage with career decision-making.

Challenges in career decision-making can occur at various stages of life and it can be seen among students in secondary school who attempt to choose their major for future career, as well as among college students who may continuously find it hard to engage in career decisions even after starting an undergraduate program (Gati \& Levin, 2014). The issue regarding career decision-making difficulties has been arising in Malaysia and may unconsciously contribute to graduate unemployment. In fact, past research demonstrated that a sample of students from National Youth Skills Training Institutes (IKBN) in Selangor also face high career decisionmaking difficulties (Mansor \& Mat Rashid, 2013).

According to Graduates Tracer Study, the statistic shows that " $69.9 \%$ of graduates in 2017 are facing unemployment because they are still seeking for a job, $9.4 \%$ need a rest, $5.5 \%$ due to family responsibilities, $5.0 \%$ are waiting for settlements to further studies and $2.6 \%$ state that work that had been offered was not suitable" (Ahmad, 2017). This phenomenon occurs maybe because of the failure of university students to decide their career pathway once they are graduated, which consequently can lead them to career decision-making difficulties. Hence, they are not able to acquire specific career goals and fail to plan their future ahead.

This present study aims to determine the relationships between negative career thoughts (decision- making confusion, commitment anxiety) and self-efficacy with career decisionmaking difficulties (lack of information, inconsistent information) among first year undergraduate students of UPM. This study can be beneficial to explore difficulties that impeding the first-year undergraduate students in career decision-making in order to maximize their capabilities in preparing their future career pathways. The findings of current study rebounded to the benefits for local assisting researchers, practitioners and educators as Copyright $\odot$ GLOBAL ACADEMIC EXCELLENCE (M) SDN BHD - All rights reserved 
references for future study of career decision-making difficulties within the Malaysian context. This is because adding new knowledge regarding this field would give a big contribution towards improving the qualities of career decision-making possess by university students which consequently reduce the number of students who are undecided about their career pathway.

\section{Literature Review}

\section{Career Decision-Making Difficulties}

Career decision-making difficulties also refer to several internal characteristics and situational responses that making boundaries towards an individual's capability to involve in career decision-making (Fabio, Palazzeschi, \& Bar-On, 2012). In addition, Gati, Krausz and Osipow (1996) previously developed a taxonomy of difficulties in career decision-making and they define career decision-making difficulties as any deviation from an "ideal career decision maker" as a possible issue that may influence the individual's decision process in this any two conceivable way: a) by impeding the individual from making a decision or b) by directing to ales than favourable decision. Specifically, there are three major categories of career decisionmaking difficulties in the proposed taxonomy; lack of readiness, lack of information and inconsistent information.

According to Gati and Kulcsar (2019), lack of readiness consists of three difficulty categories which are lack of motivation that describes individual lack of willingness to make a decision, general indecisiveness that reflects the general difficulty in making decisions and dysfunctional beliefs that refer to dysfunctional thoughts about the career decision-making process. Next, lack of information encompassed four difficulty categories. First, lack of knowledge while taking appropriate steps involved in career decision-making. Second, lack of information about individuals themselves such as career preferences, vocational interests, work values, abilities and skills. Next, lack of information about preferable occupations or majors and lastly, lack of information about the method of acquiring additional information that may assist the process of career decision-making. Furthermore, inconsistent information consists of three difficulty categories which are unreliable information that explains contradictory information about considered occupations, internal conflicts that describe internal confusion and external conflicts caused by contradiction between opinions of two significant others (Gati \& Kulcsar, 2019)

In addition to that, Sidiropoulou-Dimakakou, Mylonas, Argyropoulou and Tampouri (2012) highlighted "lack of correct information regarding the labor market can provoke confusion because sometimes the information that one uses are not recent or is not suitably presented by their source, without excluding the case where he/she unconsciously manipulates the information because of his/her personal stance, beliefs and values". Plus, students who are facing obscurity regarding career-related information probably encountered an issue with inconsistent and lacking information. Besides, Chen and Liew (2015) conduct a study towards Malaysian's Private Higher Educational Institutes and found that career decision-making difficulties are the latest issue faced by Malaysian's university students. Therefore, career decision-making difficulties are becoming a topic of concern that needs further research in order to improve the process of career decision-making especially among Malaysian university students. 


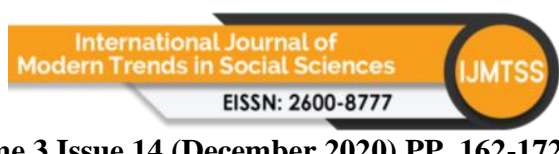

Volume 3 Issue 14 (December 2020) PP. 162-172

DOI 10.35631/IJMTSS.3140013

\section{Negative Career Thoughts}

Previous literature defines negative career thoughts as unfavourable results of individual thoughts in relation to beliefs, attitudes and feelings associated with career decision-making and planning (Sampson, Peterson, Lenz, Reardon, \& Saunders, 1996). Negative career thoughts are conceptualized based on Cognitive Information Processing (CIP) and it starts with an individual exploring a gap or most likely refers as a career problem in their career development (Werner, 2017). Therefore, "CIP theory encourages practitioners to identify clients' negative career thoughts in the context of the Pyramid of Information Processing and CASVE cycle to help them overcome cognitive barriers to career problem solving and decision-making" (Sargent \& Lenz, 2017). This is because individuals with negative career thoughts are likely to avoid facing career selection and career decision-making (Jamali, Araqi \& Kalantarkousheh, 2015).

Career Thoughts Inventory (CTI) was utilized to measure negative career thoughts and the nature of those feelings and this assessment also includes three other dimensions that inform the nature of negative career thoughts (Hasan, 2015). Sampson, Peterson, Lenz, Reardon, and Saunders (1999) emphasized that there were three construct or dimensions which include decision-making confusion (DMC), commitment anxiety (CA) and external conflicts (EC). In addition, previous literature suggested that decision-making confusion (DMC) associated with individuals who had encountered difficulties identifying their skills or attributes, perhaps uncertain about their abilities (Kronholz, 2017). Furthermore, Austin and Cilliers (2011) stated that commitment anxiety (CA) refers to an inability to commit specific career choices along with anxiety about the result of decision-making itself while external conflicts (EC) reflect the inability to balance important personal perceptions and significant others.

\section{Self-Efficacy}

Bandura (1977) states self-efficacy is an individual's belief in his/her ability to accomplish a task or to deal with a circumstance. According to Atta, Akhter, Shujja and Shujaat (2013) on their study about the impact of self-efficacy on negative career thoughts in university graduates, it aims to explore self-efficacy as the determinant of negative career thoughts. The result of the study showed that self-efficacy was negatively correlated with negative career thoughts and its construct scales through correlation analysis. Furthermore, findings also found that selfefficacy as a significant negative predictor of negative career thoughts total and its construct through linear regression analysis. Thus, this study demonstrated an evidence showing the importance of self-efficacy to avoid problems that may jeopardize one's career decisionmaking process such as negative career thoughts. Meanwhile, self-efficacy acts as an independent variable in the present study aimed to determine to what extent it influences career decision-making difficulties. This is mainly because individuals who possess low career selfefficacy failed to think that they can magnificently choose a career or learn how to gain the skill of choosing a career (Hanks, 2018). Furthermore, Reddan (2015) emphasized that "low self-efficacy expectations regarding a particular behaviour could lead to avoidance of those behaviours, whereas stronger self-efficacy expectations would more likely lead individuals to approach behaviour".

\section{Materials and Methods}

\section{Respondents}

The target population for the present study was the first-year undergraduate students of University Putra Malaysia. Students of UPM are the one and only respondents that are eligible Copyright (C) GLOBAL ACADEMIC EXCELLENCE (M) SDN BHD - All rights reserved 


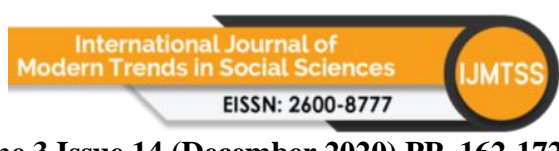

Volume 3 Issue 14 (December 2020) PP. 162-172

DOI 10.35631/IJMTSS.3140013

to participate in this study students because they often encountered troubles while making a career decision. Stebleton and Diamond (2018) emphasized that "first year students enter college with significant concerns about career and major decision-making, including questions about purpose, vocation, and meaning. Some students have opportunities to actively explore and engage in the reflection process, yet many do not". Therefore, it is necessary to make a good career decision to avoid career decision-making difficulties that may jeopardize the overall future career pathway of university students.

Survey questionnaires are utilized for data collection and the sampling technique employed to collect data from the respondents was stratified random sampling. The sample size in the current study was 368 students. The researcher divided the total of first year undergraduate students according to the selected colleges into two categories which are male and female. The number of male students was 40 while female students were 52. At first, the researcher seeks permissions from four selected colleges to conduct a research among first year undergraduate students. A formal letter was sent prior to conducting the research to the principal of each college. The permission includes approval from the Principal of the college. Each of the respondents needs to fill up all of the sections in the questionnaire. Respondents were informed that all of the information given, and responses collected will remain confidential. Respondents also are free to decline or withdraw from taking part in this study. This is to ensure that the researcher follows the rule and regulation of proper data collection.

\section{Measures}

\section{Career Thoughts Inventory (CTI)}

Sampson, Peterson, Lenz, Reardon and Saunders (1996) developed Career Thoughts Inventory (CTI) to measure negative career thoughts within an individual that acts as a barrier to career decision-making and problem-solving. CTI composed of 48 items on negative career thoughts, scored on four points Likert-type scale ranging from strongly disagree (0), disagree (1), agree (2) and strongly agree (3) by the respondents. The CTI provides a total score and scores for three construct scales. The three subscales are; a) Decision-Making Confusion - DMC (14 items), which refers to individual incompetence to perform or maintain decision-making process as a result of fragile emotions and/or lack of comprehension on decision-making process itself, b) Commitment Anxiety - CA (10 items) refers to individual incompetence to be responsible for making specific career choice and generalized anxiety about the result of career decision-making process and c) External Conflict - EA (5 items) scale reflects to individual failure to adjust the significance of one's self-recognition with the importance of contribution from significant others, bringing in a hesitance to accept responsibility for decision making. The reliability of CTI shown that internal consistency (Cronbach's $\alpha$ ) for CTI total score ranged from .97 to .93 . The three construct scale alpha coefficients were reported as follows: $\mathrm{DMC}(\alpha=.90$ to .94$), \mathrm{CA}(\alpha=.79$ to .91$)$ and $\mathrm{EC}=(\alpha=.74$ to .81$)$. The present study only applied two subscales of CTI which are decision-making confusion and commitment anxiety.

\section{General Self-Efficacy Scale (GSE)}

Based on Schwarzer and Jerusalem (1995), General Self-Efficacy Scale (GSE) is a self-report assessing self-efficacy and was developed to evaluate the coping ability of daily living. This instrument consists of 10 items scored on a four-point Likert-type scale from not at all true (1), hardly true (2), moderately true (3) and exactly true (4). Previous research conducted by Javed 
and Tariq (2016) demonstrated that the reliability of GSE was $\alpha=.80$. The higher score indicates more self-efficacy.

\section{Career Decision-Making Difficulties Questionnaire (CDDQ)}

According to Gati, Krausz and Osipow (1996) in general theoretical taxonomy of career decision-making difficulties, Career Decision-Making Difficulties Questionnaire (CDDQ) was developed to measure areas of difficulties in making a career decision. The original CDDQ was comprised of 44 items but the present study utilized a revised shortened version comprises of 34 items (Gati \& Saka, 2001). CDDQ is divided into three major categories/dimensions: 1) Lack of Readiness, 2) Lack of Information and 3) Inconsistent Information. Career DecisionMaking Difficulties Questionnaire (CDDQ) is scored based on a 5-points Likert-type scale (1= does not describe me, to $5=$ describes me well) adapted by the Turkish version of CDDQ as a five-point grading (Bacanli, 2008) and mean of each major category were calculated. Gati and Saka (2001) state that internal reliabilities for the shortened version among Israeli young adults with age range from 19 to 23 were reported as follows: total CDDQ $(\alpha=.88)$, Lack of Readiness $(\alpha=.61)$, Lack of Information $(\alpha=.87)$ and Inconsistent Information $=(\alpha=.77)$. This present study-only applied two major categories of CDDQ; lack of information and inconsistent information which consist only 22-items in order to assess individuals' career decision-making difficulties.

\section{Results}

Descriptive Statistical Analysis

Table 1: Respondents' Demographic Characteristics $(n=368)$

\begin{tabular}{|c|c|c|c|c|c|c|}
\hline Variable & $\mathbf{n}$ & $\%$ & Mean & S.D. & Min. & Max. \\
\hline Age (Years) & & & 19.78 & 0.94 & 18 & 24 \\
\hline 18 & 1 & 0.3 & & & & \\
\hline 19 & 164 & 44.6 & & & & \\
\hline 20 & 149 & 40.5 & & & & \\
\hline 21 & 30 & 8.2 & & & & \\
\hline 22 & 18 & 4.9 & & & & \\
\hline 23 & 4 & 1.0 & & & & \\
\hline 24 & 2 & 0.5 & & & & \\
\hline \multicolumn{7}{|l|}{ Race } \\
\hline Malay & 309 & 84.0 & & & & \\
\hline Chinese & 28 & 7.6 & & & & \\
\hline Indian & 16 & 4.3 & & & & \\
\hline Others & 15 & 4.1 & & & & \\
\hline \multicolumn{7}{|l|}{ Gender } \\
\hline Male & 160 & 43.5 & & & & \\
\hline Female & 208 & 56.5 & & & & \\
\hline \multicolumn{7}{|l|}{ College } \\
\hline Kolej Empat Belas & 82 & 22.3 & & & & \\
\hline \multirow[t]{2}{*}{ Kolej Dua Belas } & 87 & 23.6 & & & & \\
\hline & 99 & 26.9 & & & & \\
\hline
\end{tabular}


Kolej Sultan

Alaeddin

Suleiman Shah

Kolej Pendeta

Za'ba

Note: $\mathrm{n}=$ Frequency, $\%=$ Percentage, S.D. $=$ Standard deviation, Min = Minimum, Max = Maximum

\section{Characteristics of the Respondents}

This section describes the personal background of the respondents. It included age, race, gender and college. The sample of the study consisted of 368 first year undergraduate students of Universiti Putra Malaysia $(n=368)$. The minimum and maximum ages of the respondents were 18 years old and 24 years old respectively. The mean age of the respondents was 19.78 years old with a standard deviation of 0.94 . As demonstrated in Table 1, results show that most respondents' ages were 19 years old $(44.6 \%)$ while the least respondents' ages were 18 years old $(0.3 \%)$. Other than that, respondents were asked to report their races. Categories of races to select from were Malay, Chinese, Indian and Others. Besides, the findings of the present study perceived Malay respondents $(84.0 \%)$ as the highest category of race out of 368 participated respondents. $7.6 \%$ of the respondents were Chinese, $4.3 \%$ were Indian and $4.1 \%$ identified as others. Besides, table 1 displays gender information for the present study. The results indicated that the majority of participants were males $(43.5 \%)$ while females made up $56.5 \%$ from a total of 368 respondents.

Respondents for the present study were recruited at four colleges in UPM which are Kolej Empat Belas, Kolej Dua Belas, Kolej Sultan Alaeddin Suleiman Shah and Kolej Pendeta Za'ba. The findings reported $22.3 \%$ of respondents were recruited from Kolej Empat Belas, $23.6 \%$ of them from Kolej Dua Belas, $26.9 \%$ of respondents were from Kolej Sultan Alaeddin Suleiman Shah and 27.2\% of them from Kolej Pendeta Za'ba.

\section{Correlational Analysis}

Table 2: Correlation between Negative Career Thoughts and Self-Efficacy with Career Decision-Making Difficulties

\section{Career Decision-Making Difficulties}

Variables

\section{Negative Career \\ Thoughts}

i) Decision-Making

Confusion

ii) Commitment

Anxiety

Self-Efficacy i) Lack of Information

ii) Inconsistent Information

Note: $* * p \leq 0.01$ 


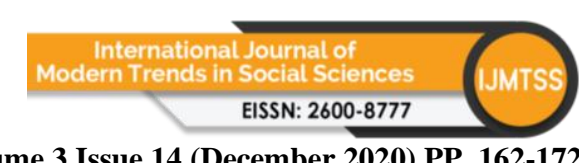

Volume 3 Issue 14 (December 2020) PP. 162-172

DOI 10.35631/IJMTSS.3140013

As shown in table 2, the result of Pearson Correlation indicated that there was a positive significant relationship between decision-making confusion and lack of information $(\mathrm{r}=0.595$, $\mathrm{p} \leq 0.01)$. The findings also demonstrated that there was a significant positive relationship between commitment anxiety and lack of information $(\mathrm{r}=0.588, \mathrm{p} \leq 0.01)$. Other than that, the result revealed that there was a significant and positive relationship between decision-making confusion and the major category of CDDQ, inconsistent information $(r=0.579, p \leq 0.01)$. From table 2, it was found that there was a significant relationship between commitment anxiety and inconsistent information $(\mathrm{r}=0.572, \mathrm{p} \leq 0.01)$. Table 2 also depicted the finding on the relationship between self-efficacy and lack of information among the respondents for the present study. The finding indicated that there was a significant negative relationship between self-efficacy and lack of information $(r=-0.388, p \leq 0.01)$. Lastly, the result of Pearson's Correlation analysis showed that self-efficacy was significantly correlated with inconsistent information $(\mathrm{r}=-0.298, \mathrm{p} \leq 0.01)$.

\section{Discussion}

This study examines the relationships between negative career thoughts and self-efficacy with career decision-making difficulties among first year undergraduate students in UPM. There was a positive significant relationship between decision-making confusion and lack of information. This means first year undergraduate students who have a higher decision-making confusion will encounter higher lack of information that will result in higher career decisionmaking difficulties. This result is consistent with the previous study which found that the CDDQ major category, lack of information has a high and positive correlation with decision making confusion score (Sidiropoulou-Dimakakou, Mylonas, Argyropoulou \& Tampouri, 2012).

Next, there was a positive significant relationship between commitment anxiety and lack of information. First year undergraduate students with greater commitment anxiety tend to experience a high level of lack of information. Thus, the finding was aligned with the previous study who proposed that commitment anxiety showed significant positive correlations with three major categories of CDDQ includes lack of information, which explained that lack of correct information about the labor market can evoke confusion (Sidiropoulou-Dimakakou, Mylonas, Argyropoulou \& Tampouri, 2012). This means that first year undergraduate students that faced career decision-making difficulties were having a hard time to acquire positive thoughts and beliefs about career. This is because they tend to think and view negatively about that particular career which consequently makes them confuse and anxious while engaging in the career decision-making process.

There was a significant and positive relationship between decision-making confusion and the major category of CDDQ, inconsistent information. This result is consistent with the previous study which found that almost study variables between CTI and CDDQ had a medium to large correlation with one another as well decision-making confusion and inconsistent information that showed positive significant relationship (Bullock-Yowell et.al, 2014).

The correlation between commitment anxiety and inconsistent information was reported to be positive and significant which means higher commitment anxiety will lead to higher inconsistent information. This finding was in line with past research proved that commitment anxiety showed significant positive correlations with three major categories of CDDQ includes inconsistent information (Sidiropoulou-Dimakakou, Mylonas, Argyropoulou \& Tampouri, 2012). Hence, both findings showed that first year undergraduate students were having Copyright (C) GLOBAL ACADEMIC EXCELLENCE (M) SDN BHD - All rights reserved 
inconsistent and less information which cause them feeling undecided about their career paths and eventually having difficulties in career decision-making.

Finding on the relationship between self-efficacy and lack of information among the respondents in UPM, indicated that there was a significant negative relationship between selfefficacy and lack of information. The negative correlation between self-efficacy and lack of information showed that higher self-efficacy will result in a low lack of information. This result was compatible with past research that revealed self-efficacy had significant negative correlations with one category of career decision-making difficulties which is lack of information (Javed \& Tariq, 2016). This result indicated that first year undergraduate students who possess higher self-efficacy will experience fewer career decision-making difficulties. Otherwise speaking, self-efficacy has taught students to believe in their ability to accomplish specific career decision-making. Thus, self-efficacy brings a positive impact in acquiring information about career paths which decreases the possibility to engage with career decisionmaking difficulties.

Next, the result of Pearson's Correlation analysis showed that self-efficacy was significantly correlated with inconsistent information. The correlation was negative which means that first year undergraduate students who have higher self-efficacy will experience lower inconsistent information. This finding was not consistent with the previous study that demonstrated selfefficacy and one major category of CDDQ, inconsistent information was not significant (Javed \& Tariq, 2016). This is because there were private, and government academic institution included in the past research that may cause differences in findings.

\section{Conclusion}

The result of this study also had contributed an important and deeper understanding on the career decision-making difficulties among first year undergraduate students. This implies that career decision-making difficulties issues may exist and should be concerned by governments, career counseling, educators and other parties so that a lot of preventive measures can be taken to assist first year undergraduate students that facing career decision-making difficulties. Other than that, the present findings can be used for potential inputs for career counseling to gain a deeper understanding of these two particular factors which initiate career decision-making difficulties. Moreover, the present findings are beneficial to career counselors in order to actively promote early career intervention by conducting a career-related test especially for first year undergraduate students to ensure that they are well-prepared for future career decision-making by using the instrumentation that were utilized in this study.

Future research conducted in this area is encouraged to extend the sample size from different academic institutions in another region to promote a better generalization of findings. Other than that, future studies also can explore the need for career intervention to explore university students' and discover specific career intervention to ensure the good qualities in career decision-making among university students. Future researchers also are recommended to include participants from post-graduate students to understand the various stages of education that will affect career decision-making difficulties. Hence, future research can significantly contribute to the comparison of career decision-making difficulties at a different level of education. 


\section{References}

Ahmad, B. (2017). 8. Statistik Pendidikan Tinggi 2017 - Bab 7: Kajian Pengesanan Graduan. Retrieved from http://mohe.gov.my/muat-turun/awam/statistik/2017-3/475-statistikpendidikan-tinggi-2017-bab-7-kajian-pengesanan-graduan

Atta, M., Akhter, N., Shujja, S., \& Shujaat, J. M. (2013). Impact of Self-Efficacy on Negative Career Thoughts in University Graduates. International Journal of Business and Social Science, 4(6), 263-269.

Austin, K., \& Cilliers, F. (2011). The psychometric relationship between career thinking and salutogenic functioning amongst unemployed adults. SA Journal of Industrial Psychology, 37(1). doi:10.4102/sajip.v37i1.969

Bacanlı, F. (2008). Career decision making difficulties of Turkish adolescents. Counseling and international perspective: global demands and Local needs. Bahçeşehir University, İstanbul, Turkey, April, 25-27.

Bandura, A. (1977). Self-efficacy: Toward a unifying theory of behavioral change. Psychological Review, 84(2), 191-215. doi:10.1037/0033-295x.84.2.191

Bullock-Yowell, E., Leavell, K. A., Mcconnell, A. E., Rushing, A. D., Andrews, L. M., Campbell, M., \& Osborne, L. K. (2014). Career Decision-Making Intervention With Unemployed Adults: When Good Intentions Are Not Effective. Journal of Employment Counseling, 51(1), 16-30. doi:10.1002/j.2161-1920.2014.00038.x

Chen, L. S., \& Liew, S. A. (2015). Factors Influencing Career Decision-Making Difficulties among Graduating Students from Malaysian Private Higher Educational Institutions. In Proceedings of 8th Asia-Pacific Business Research Conference.

Proceedings of 8th Asia-Pacific Business Research Conference, (February).

Fabio, A. D., Palazzeschi, L., \& Bar-On, R. (2012). The role of personality traits, core selfevaluation, and emotional intelligence in career decision-making difficulties. Journal of Employment Counseling, 49(3), 118-129. doi:10.1002/j.2161-1920.2012.00012.x

Gati, I., \& Kulcsar, V. (2019). Review of the Career Decision-making Difficulties Questionnaire (CDDQ). In Stoltz, K. B. and Susan R. Barclay, S.R. (Eds.). A comprehensive guide to career assessment (7th ed.). Broken Arrow, OK: National Career Development Association. In press.

Gati, I., \& Levin, N. (2014). Counseling for Career Decision-Making Difficulties: Measures and Methods. The Career Development Quarterly, 62(2), 98-113. doi:10.1002/j.21610045.2014.00073.x

Gati, I., \& Saka, N. (2001). Internet-Based Versus Paper-and-Pencil Assessment: Measuring Career Decision-Making Difficulties. Journal of Career Assessment, 9(4), 397-416. doi:10.1177/106907270100900406

Gati, I., Krausz, M., \& Osipow, S. H. (1996). A taxonomy of difficulties in career decision making. Journal of Counseling Psychology, 43(4), 510-526. doi:10.1037/00220167.43.4.510

Hanks, J. (2018). Fear and Career Decision-Making Difficulties: Guiding Individuals With Career Indecisiveness. Brigham Young University. Retrieved from https://scholarsarchive.byu.edu/studentpub/244

Hasan, L. (2015). Ready or Not: Career Readiness Informed by the Career Thoughts Inventory. Retrieved from https://knowledge.e.southern.edu/senior_research/181

Jamali, Y., Araqi, V., \& Kalantarkousheh, S. M. (2015). Function of dysfunctional career thoughts, procrastination and career indecision among Allameh Tabatab'I University Students. European Online Journal of Natural and Social Sciences, 4(1), 57-65. 
Javed, Z., \& Tariq, O. (2016). Career-decisions, Self-efficacy and Self-esteem among Students of Private and Government Academic Institutions. Pakistan Journal of Social and Clinical Psychology, 14(2), 42-46.

Kronholz, J. (2017). The Relationship among Dysfunctional Career Thoughts, Interest Profile Elevation, and Ability Self-Estimates (Doctoral dissertation, The Florida State University).

Leo, M. (2018, June 29). Fresh Graduate Unemployment in Malaysia. Retrieved from https://eduadvisor.my/articles/what-didnt-know-fresh-graduate-unemploymentmalaysia-infographic/

Moaz Nair. (2018, September 5). Graduates must hone their soft skills if they want jobs. $\quad$ Retrieved from https://www.freemalaysiatoday.com/category/opinion/2018/09/05/graduatesmust- hone-their-soft-skills-if-they-want-jobs/

Reddan, G. (2015). Enhancing Students' Self-Efficacy in Making Positive Career Decisions. Asia-Pacific Journal of Cooperative Education, 16(4), 291-300.

Sampson, J. P., Peterson, G. W., Lenz, J. G., Reardon, R. C., \& Saunders, D. E. (1996). Improving your career thoughts: A workbook for the Career Thoughts Inventory. Odessa, Florida: Psychological Assessment Resources.

Sampson, J. P., Saunders, D. E., Reardon, R. C., Lenz, J. G., \& Peterson, G. W. (1999). The Use and Development of the Career Thoughts Inventory. Tallahassee, Florida: Psychological Assessment Resources.

Sargent, A. C., \& Lenz, J. G. (2017). The Career Thoughts Inventory (CTI) and CTI workbook: A purposeful integration of theory, research, and practice in career assessment and intervention. Career Planning and Adult Development Journal, 33(4), 45-54.

Schwarzer, R., \& Jerusalem, M. (1995). Generalized self-efficacy scale. Measures in health psychology: A user's portfolio. Causal and control beliefs, 1(1), 35-37.

Sidiropoulou-Dimakakou, D., Mylonas, K., Argyropoulou, K., \& Tampouri, S. (2012). Career Decision-Making Difficulties, Dysfunctional Thinking and Generalized SelfEfficacy of University Students in Greece. World Journal of Education, 2(1), 117130.

Stebleton, M. J., \& Diamond, K. K. (2018). Advocating for Career Development and Exploration as a High-Impact Practice for First-Year Students. Journal of Colleg and Character, 19(2), 160-166.

Werner, B. J. (2017). Assessing Career Decision-Making Status: The CASVE Cycle Questionnaire (Master's Thesis). University of Southern Mississippi, United States. Retrieved from https://aquila.usm.edu/cgi/viewcontent.cgi?article=1300\&context=masters_theses 